This item was submitted to Loughborough's Research Repository by the author.

Items in Figshare are protected by copyright, with all rights reserved, unless otherwise indicated.

\title{
Microstructure and microwave dielectric properties of 3D printed low loss Bi2Mo2O9 ceramics for LTCC applications
}

PLEASE CITE THE PUBLISHED VERSION

https://doi.org/10.1016/j.apmt.2020.100862

PUBLISHER

Elsevier

VERSION

AM (Accepted Manuscript)

\section{PUBLISHER STATEMENT}

This paper was accepted for publication in the journal Applied Materials Today and the definitive published version is available at https://doi.org/10.1016/j.apmt.2020.100862.

\section{LICENCE}

CC BY-NC-ND 4.0

\section{REPOSITORY RECORD}

Goulas, Athanasios, George Chi-Tangyie, Dawei Wang, Shiyu Zhang, Annapoorani Ketharam, Vaidhy Vaidhyanathan, lan Reaney, et al.. 2020. "Microstructure and Microwave Dielectric Properties of 3D Printed Low Loss $\mathrm{Bi}_{2} \mathrm{mo}_{2} \mathrm{O}_{9}$ Ceramics for LTCC Applications". Loughborough University.

https://hdl.handle.net/2134/13108229.v1. 


\title{
Microstructure and microwave dielectric properties of 3D printed low loss $\mathrm{Bi}_{2} \mathrm{Mo}_{2} \mathrm{O}_{9}$ ceramics for LTCC applications
}

\author{
Athanasios Goulas ${ }^{1 *}$, George Chi-Tangyie ${ }^{2}$, Dawei Wang ${ }^{3}$, Shiyu Zhang ${ }^{1}$, Annapoorani Ketharam ${ }^{2}$, \\ Bala Vaidhyanathan ${ }^{2}$, Ian M. Reaney ${ }^{3}$, Darren A. Cadman ${ }^{1}$, Will G. Whittow ${ }^{1}$, John (Yiannis) C. \\ Vardaxoglou ${ }^{1}$, Daniel S. Engstrøm ${ }^{1}$ \\ ${ }^{1}$ Wolfson School of Mechanical, Electrical and Manufacturing Engineering, Loughborough University, LE11 3TU, United \\ Kingdom \\ 2Department of Materials, Loughborough University, Loughborough, LE11 3TU, United Kingdom \\ ${ }^{3}$ Department of Materials Science and Engineering, University of Sheffield, Sheffield, S1 3JD, United Kingdom.
}

*a.goulas@lboro.ac.uk

\section{ABSTRACT}

Low sintering temperature, ultra-low loss microwave ceramics are envisaged as future dielectrics for fabricating low temperature co-fired ceramic (LTCC) components for 5G applications. Low sintering temperature bismuth molybdate $\beta-\mathrm{Bi}_{2} \mathrm{Mo}_{2} \mathrm{O}_{9}$ ceramic powders have been synthesised using a solidstate reaction method. Their additive manufacture and resulting microwave properties are reported for the first time. Optimum densification occurred for 3D printed samples sintered 4 hours at $670^{\circ} \mathrm{C}$ which resulted in a maximum relative density $\left(\rho_{r}\right)$ of $92 \%$, relative permittivity $\left(\varepsilon_{r}\right)$ of 34 , dielectric loss (tan $\delta$ ) of 0.0007 , giving a microwave quality factor ( $Q x f)$ of $10,050 \mathrm{GHz}$, properties attractive for LTCC applications.

Keywords: additive manufacturing; 3D printing; microwave ceramics; dielectrics; $\mathrm{LTCC} ; \mathrm{Bi}_{2} \mathrm{Mo}_{2} \mathrm{O}_{9}$. 


\section{Highlights}

- $\quad \beta-\mathrm{Bi}_{2} \mathrm{Mo}_{2} \mathrm{O}_{9}$ ceramics were fabricated via $\mathrm{AM}$ using a powder-to-product approach.

- Sintering 4 hours at $670^{\circ} \mathrm{C}$ resulted in $\varepsilon_{r}=34.2$ and $Q \times f=10,050 \mathrm{GHz}$.

- The 3D printed samples achieved a remarkably low dielectric loss of $\tan \delta=0.0007$.

- Sintering above $670^{\circ} \mathrm{C}$ promoted $\beta \rightarrow \alpha+\gamma$ phase transition, that reduced $\varepsilon_{r}$.

\section{Graphical abstract}

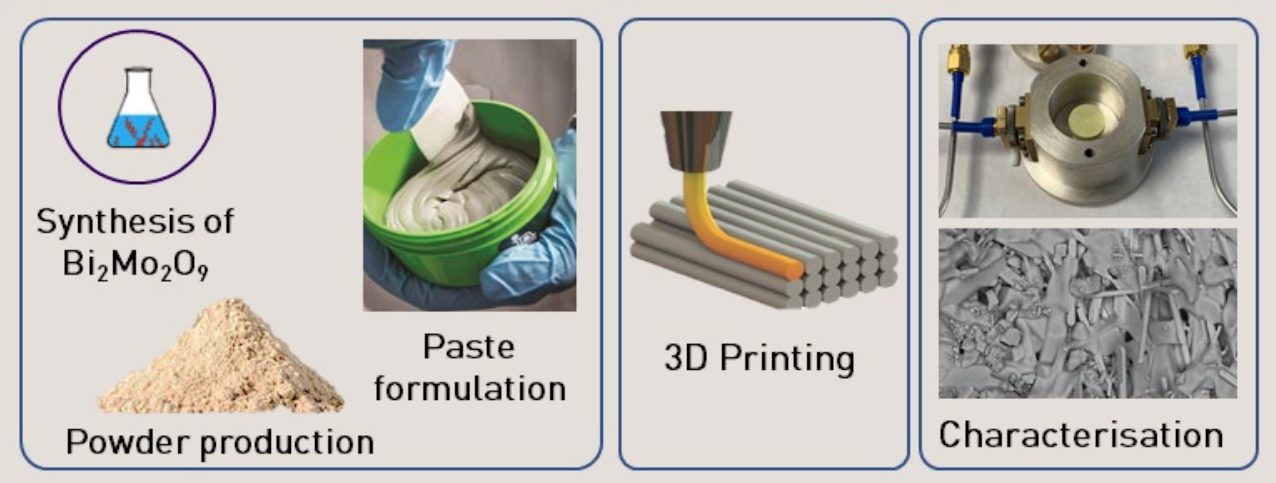




\section{Introduction}

Microwave (MW) ceramics are well established as the dielectric materials of choice for applications within microwave and mobile telecommunications such as global positioning, Wi-Fi, dielectric resonators (DR), filters, duplexers, capacitors and dielectric substrates [1-3].

Their inherent properties such as relative permittivity $\left(\varepsilon_{r}\right)$, high quality factor $(Q \times f)$ and low dielectric loss ( $\tan \delta)$, have set the standard for making mobile devices with a significantly small form factor, low latency and high data transfer rates. Such performance characteristics are necessary to support the transition to fifth generation (5G) cellular networks, where low latency and low power consumption are required. $5 \mathrm{G}$ mobile phone base stations and handheld devices should consist of components that exhibit the following properties: medium relative permittivity values $\left(25<\varepsilon_{r}<50\right)$ and high quality factor $(Q \times f>3,000 \mathrm{GHz})[4-7]$, resulting from low dielectric loss $(\tan \delta<0.001)$ [8].

Current MW dielectric ceramics are fabricated through traditional powder processing routes that require high densification temperatures $\left(>1000^{\circ} \mathrm{C}\right)$, leading to considerable energy consumption and $\mathrm{CO}_{2}$ emissions together with associated tooling costs [9]. The use of low temperature co-fired ceramics (LTCCS) [10-12], ultralow temperature co-fired ceramics (ULTCCS) [13-15] and cold sintering co-fired ceramics (CSCCs), in which materials can be densified at processing temperatures $<300^{\circ} \mathrm{C}[16-18]$, is set to revolutionise the way modern dielectric components are fabricated. Aside from the obvious benefit of energy saving and reduced emissions, lower sintering temperatures also favour co-firing with common, low-cost electrode materials, such as silver, aluminium, copper or gold, that are typically used in electronic circuits [19-23].

Zhou et al. were the first to report the synthesis and associated MW dielectric properties of ceramic compounds in the $\mathrm{Bi}_{2} \mathrm{O}_{3}-\mathrm{MoO}_{3}$ binary system. The monoclinic $\beta-\mathrm{Bi}_{2} \mathrm{Mo}_{2} \mathrm{O}_{9}(\beta-\mathrm{BMO})$ phase exhibited the highest relative permittivity, $\varepsilon_{r} \approx 38$, together with a MW quality factor, $Q \times f \approx 12,500 \mathrm{GHz}$. However, chemical incompatibility with silver, posing as a candidate electrode for co-firing was also identified [24]. In their follow up work, Zhou et al further investigated the microwave dielectric properties of the $\mathrm{Bi}_{2} \mathrm{O}_{3}-\mathrm{MoO}_{3}$ binary system. A total of eight simple and multi-phase compounds were identified with $17<\varepsilon_{r}<38$ and $1900<Q \times f<21,800 \mathrm{GHz}$. The chemical compatibility of the $\alpha-$ $\mathrm{Bi}_{2} \mathrm{Mo}_{3} \mathrm{O}_{12}$ and $\beta-\mathrm{Bi}_{2} \mathrm{Mo}_{2} \mathrm{O}_{9}$ phases with aluminium permitted their use for co-fired components [25]. LTCC modules are fabricated using a multilayer process in which metal structures are printed onto the surface of green tape which is then multi-layered and densified at high temperature (850 to $900{ }^{\circ} \mathrm{C}$ ) to create a MW circuit. Despite the high densities achieved (>90\%), such forming approaches suffer 
from a lack of geometric freedom; i.e. only planar architectures may be produced and further machining is required to add greater complexity to the shape.

Additive manufacturing ( $A M)$ is well known for offering great manufacturing flexibility by allowing fabrication of geometrically complex parts, that would otherwise be challenging to realise through the conventional means [26]. Together with the ability to process virtually any material and its economical usage, AM is envisaged as a promising candidate to revolutionise electronics manufacturing $[27,28]$.

Direct Ink Writing (DIW), also known as micro-extrusion [29] or robocasting [30], is a forming technique in the material extrusion AM family, that enables affordable and easy manufacture of ceramics [31]. DIW uses high solid loading colloidal suspensions (i.e. pastes, slurries), to fabricate free standing structures of high-aspect ratios, without the need of supporting structures, similar to powder bed fusion and vat-based AM processes [32]. The added benefit of using DIW processing for AM of ceramics is the possibility to produce final parts with periodic features and tailored properties by controlling the 3D printer's toolpath $[33,34]$. Such examples include shaping of more advanced RF devices, such as single material Fresnel zone plate lenses $[35,36]$ or multi-material structures with tuneable properties (e.g. controllable permittivity) [37-39] and functional devices by printing both electrodes and dielectrics $[40,41]$.

However, AM-produced structures do not always possess the properties and performance of bulk materials, due to process-related limitations resulting in printed parts with reduced density or poor surface quality that often affect performance $[42,43]$. Therefore, this study reports for the first time, the MW dielectric performance of BMO ceramics synthesised via solid-state reaction method and 3D printed using DIW. The following sections assess the powder feedstock material and the rheology of the printing medium that has been used, together with the microstructural, microwave, physical properties and phase evolution during sintering. 


\section{Material \& Methods}

\subsection{Materials}

The $\beta$ - BMO powder was synthesised using a solid-state reaction method. High purity raw chemicals, $\mathrm{Bi}_{2} \mathrm{O}_{3}$ (99.9\%, Acros Organics) and $\mathrm{MoO}_{3}$ (>99\%, Acros Organics) were weighed stoichiometrically $\left(\mathrm{Bi}_{2} \mathrm{O}_{3}: \mathrm{MoO}_{3}=1: 2\right)$ and then planetary ball-milled 4 hours in isopropanol. Afterwards, the dried mixed powders were calcined 4 hours at $630^{\circ} \mathrm{C}$. The calcined powder was then milled using a rotary mill and sieved through a $100 \mu \mathrm{m}$ aperture laboratory sieve.

\subsection{Ceramic paste formulation}

A binder mix consisting of ethylene glycol diacetate (7.1 wt.\%, Sigma Aldrich, Dorset, UK) as dispersant, ethyl cellulose ( $2 \mathrm{wt. \%}$, Sigma Aldrich, UK) and propylene carbonate (1.9 wt.\%, Sigma Aldrich, Dorset, UK) as viscosity modifier and binder, respectively, diisononyl phthalate (2.7 wt.\%, Sigma Aldrich, Dorset, UK) as plasticiser, and ammonium lauryl sulphate (0.3 wt.\%, Sigma Aldrich, Dorset, UK) as surfactant was prepared. The BMO powder was slowly incorporated into the binder mix following by mixing and then topped up with de-ionised water (2.9 wt.\%). The paste was homogenised thrice using a planetary mixer (Thinky ARM 310, Thinky Inc., Laguna Hills, California USA) at 1500 rpm for 2 mins with pulses of 2 hours. The total solid content in the paste was $\approx 83.1$ wt.\%.

\subsection{Additive manufacturing and thermal post-processing.}

All additively manufactured test samples were made using a multi-process additive manufacturing kit (High-Resolution Engine, Hyrel3D, Norcross, GA, USA), equipped with a syringe dispensing module (SDS-5, Hyrel3D, Norcross, GA, USA), using 5ml luer-lock syringes (Becton Dickinson, Franklin Lakes, New Jersey, USA) and $0.5 \mathrm{~mm}$ tapered metallic needles of $18.25 \mathrm{~mm}$ in length (Adhesive Dispensing, Milton Keynes, United Kingdom). A combination of printing speed of $5 \mathrm{~mm} / \mathrm{s}$, layer thickness of 0.2 $\mathrm{mm}, 0.45 \mathrm{~mm}$ hatch spacing; providing a $10 \%$ overlap of the extruded filaments, and a constant positive displacement value of 86 pulses per microlitre, were used to print cylindrical test samples of $10 \mathrm{~mm}$ in diameter and $4 \mathrm{~mm}$ thickness. The test samples were first modelled using CAD and G-code for printing was generated using Hyrel3D's inbuilt slicing software.

The 3D printed samples were left to dry at room temperature for a minimum of 24 hours and were then thermally debinded in a furnace using a ramp rate of $1^{\circ} \mathrm{C} / \mathrm{min}$ to $500^{\circ} \mathrm{C}$, whilst holding at $100^{\circ} \mathrm{C}$, $200{ }^{\circ} \mathrm{C}, 300{ }^{\circ} \mathrm{C}, 400{ }^{\circ} \mathrm{C}$ and $500{ }^{\circ} \mathrm{C}$ for 2 hours each. The binder removal process was slow in order to 
avoid the cracking and/or warping of the 3D printed samples. The debinded samples were sintered between $640-680^{\circ} \mathrm{C}$ for $2-4$ hours with heating and cooling rates of $3{ }^{\circ} \mathrm{C} / \mathrm{min}$; Figure 1 .

\subsection{Characterisation methods}

The particle size distribution of the milled BMO powder was confirmed using a combination of laser diffraction (Scirocco 2000, Mastersizer, UK) and scanning electron microscopy (SEM) (TM3030, Hitachi High Energy Technologies, etc.).

Rheological properties of the BMO paste were measured using a high shear rheometer (Physica MCR 101, Anton Paar) with a parallel-plate geometry of $25 \mathrm{~mm}$ in diameter and $0.5 \mathrm{~mm}$ gap. To determine, complex viscosity $(\eta)$, shear stress $(\sigma)$, storage $\left(G^{\prime}\right)$ and loss modulus $(G)^{\prime \prime}$, an amplitude sweep was performed using a continuous strain rate ramp from 0.01 to $100 \mathrm{~s}^{-1}$.

The phase structure and purity of the as-synthesised BMO powder together with any potential phase changes during sintering, were investigated with an X-Ray diffractometer (D2 Phaser, Bruker AXS, Karlsruhe, Germany) using CuK $_{\alpha}$ radiation at $\lambda=1.54054 \AA$, operating at $30 \mathrm{kV}$ and $10 \mathrm{~mA} .1 \mathrm{~mm}$ divergence and a $3 \mathrm{~mm}$ anti-scatter slits were used. Diffraction patterns were collected from $10-60^{\circ}$ $2 \vartheta$, using a $0.02^{\circ}$ step size and $15 / \mathrm{min}$ sample rotation. Collected data were analysed using Bruker's proprietary software (DIFFRAC.EVA 5.2, Bruker AXS, Karlsruhe, Germany).

The density of the sintered samples was measured using the Archimedes principle [44]. Results are reported as an average of three different 3D printed samples, together with their standard deviation.

The impact of sintering temperature on the ceramic microstructure was assessed using a scanning electron microscope (SEM) (TM3030, Hitachi High Energy Technologies, etc.). 3D printed test samples were embedded in epoxy resin (EpoThin2, Buehler, Illinois, USA) and prepared by grinding using silicon carbide paper of P1200 grit size, followed by polishing on a cloth impregnated with a $0.05 \mu \mathrm{m}$ alumina suspension. To prevent charging during SEM, samples were sputter coated with a gold/palladium alloy in an 80:20 wt.\% ratio, for $60 \mathrm{~s}$ at 25 mA (Quorum Q150T, Quorum, Edwards, Hastings, UK).

Relative permittivity $\left(\varepsilon_{r}\right)$, dielectric loss $(\tan \delta)$ and quality factor $(Q x f)$ of additively manufactured BMO samples were determined by placing the cylindrical 3D printed test samples of $10 \mathrm{~mm}$ diameter and 4 $\mathrm{mm}$ thickness, into a $24 \mathrm{~mm} \mathrm{TE}_{01 \delta}$ cavity resonator (QWED, Warsaw, Poland), measuring the transmission coefficient of the loaded cavity resonator, connected to a Vector Network Analyser (VNA) (MS465B22, Anritsu, Japan) using coaxial cables [45]. The properties were calculated using QWED's 
proprietary software. Results are reported as an average of three different printed samples, together with standard deviation.

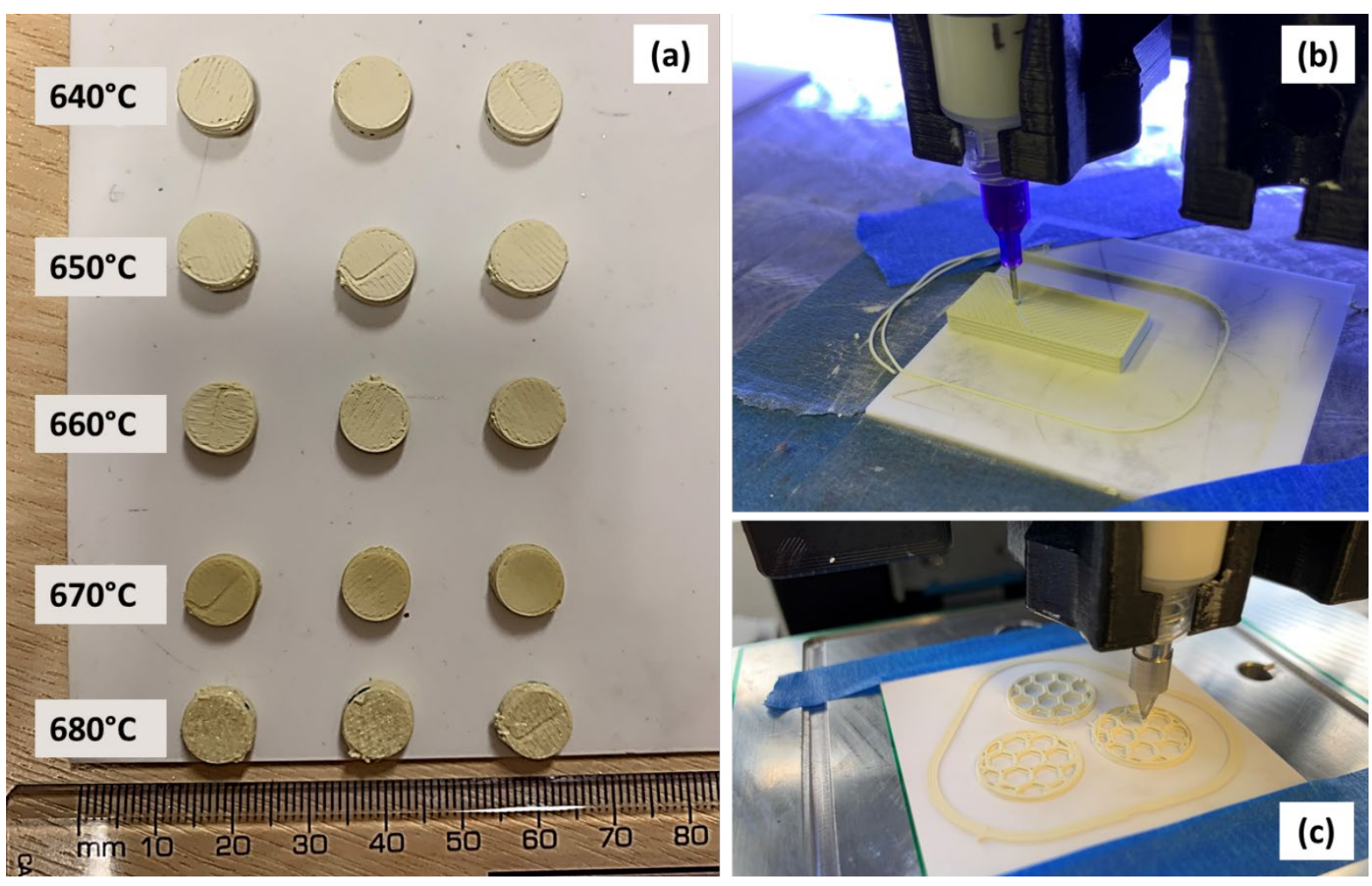

Figure 1 - Photos of (a) 3D printed and sintered BMO test samples, $(b, c) 3 D$ printing with BMO ceramic paste. 


\section{Results \& Discussion}

\subsection{Particle size of BMO ceramic powders}

Figure $2 \mathrm{a}$ shows the particle size distribution from 3 different powder samples, acquired via laser diffraction, of the BMO power, ball milled immediately after calcination. The analysis revealed a multimodal particle size distribution, ranging from $1-50 \mu \mathrm{m}$ with a particle size median at $D_{50}=11.19$ $\pm 4.17 \mu \mathrm{m}$. Polydisperse particle distributions, such as the one used in this study, are preferred in colloidal processing [46], since they allow for higher solid loadings ( $>50$ vol.\%); i.e. the quantity of ceramic particles contained in the suspension. This results in printing mediums that possess rheological properties suitable for extrusion additive manufacturing [47-49]. Additionally, a high solid loading reduces shrinkage during drying, which is known to cause microcracking [50-52], leading to catastrophic failures during sintering. Complementary analysis using SEM, confirmed the results from the particle size analysis. Figure $\mathbf{2} \mathbf{b}$ depicts BMO powder particles of subangular external morphology and approximate particle diameters of 2 to $16 \mu \mathrm{m}$ in diameter, that falls within the previously measured particle size distribution.
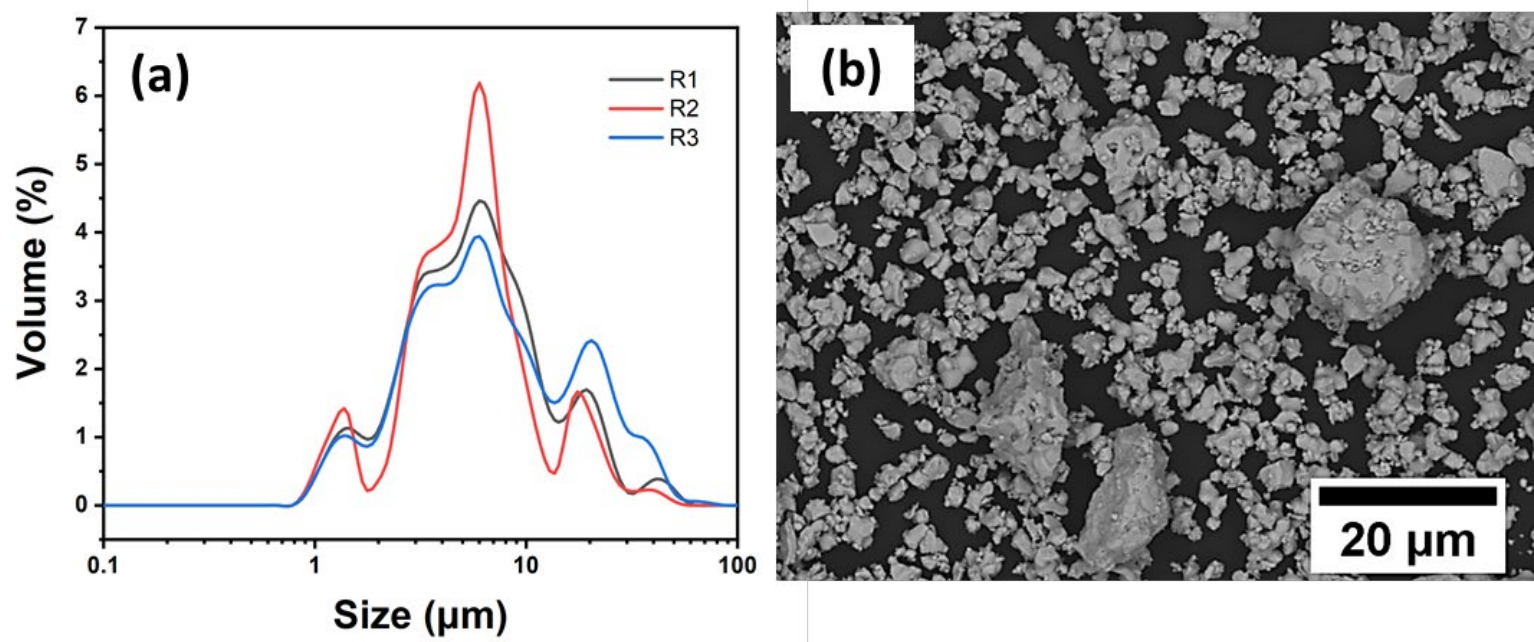

Figure 2 - (a) Particle size distribution of the BMO powders, (b) SEM micrograph of BMO particles.

\subsection{Rheological assessment of the ceramic paste}

Figure 3 presents the rheology data acquired from the oscillatory shear stress sweeps and shear stress vs. shear rate of the BMO ceramic paste. Figure 3a contains the storage modulus $\left(G^{\prime}\right)$, loss modulus $\left(G^{\prime \prime}\right)$ and complex viscosity $(\eta)$ curves of the ceramic paste in the shear rate range of $0.01-100 \mathrm{~s}^{-1}$. For low shear values $\left(<0.01 \mathrm{~s}^{-1}\right)$, storage modulus of the ceramic paste is greater than its loss modulus, meaning that the paste has a solid-like behaviour. This is a fundamental requirement for materials to 
be used with the direct ink writing process, since the material should be rigid enough to retain its shape right after extrusion, together with having enough strength and rigidity to support the weight of the subsequent printed layers [52,53].

The relation between the storage and loss moduli is kept the same, until a maximum shear deformation is reached, known as the yield stress $\left(\tau_{0}\right)$, where the storage and loss curves intersect and the ceramic paste transitions from solid- to liquid-like. Therefore, the yield stress $\left(\tau_{0}\right)$ is the amount of stress required to facilitate flow. From a practical point of view, knowledge of the $\tau_{0}$ gives an account of the approximate pressure that needs to be applied to the piston when a pneumatics-based 3D printing system is to be used. The yield stress point of $\tau_{0}=60.9 \mathrm{kPa}$ at $\dot{\gamma}=0.28 \mathrm{~s}^{-1}$ strain rate was calculated using an intersection script (Origin 2020, OriginLab Corporation, Northampton, MA, USA) between the storage and loss modulus curves.

The shear rate versus complex viscosity curves are also shown, where the BMO ceramic paste exhibited a continuous reduction of its viscosity with increasing shear deformation. This is due to the change in orientation of the polymers' molecular chains that align with the direction of the flow $[50,54]$. This phenomenon is a characteristic of non-Newtonian fluids, commonly known as shear thinning and is another significant requirement for materials for direct ink writing [55]. The shear thinning behaviour of the BMO paste was further assessed, by fitting the shear rate vs. shear rate curve to the Herschel - Bulkley theoretical model (Equation 1), that is used to describe yieldpseudoplastic materials [55]:

Herschel-Bulkley model:

$$
\tau(\dot{\gamma})=\tau_{0}+k \cdot \dot{\gamma}^{n}
$$

Equation 1

The previously measured yield stress value $\left(\tau_{0}\right)$ was inputted in the model, to allow for more precise calculation of the consistency $(k)$ and flow behaviour index $(n)$ values. Fitting using the least squares method $\left(R^{2}=0.99\right)$, resulted in a consistency index value of $k=278 \pm 10 \mathrm{~Pa} \cdot \mathrm{s}$ and a flow index of $n=$ $0.48 \pm 0.0009$; shown in Figure $\mathbf{3 b}$. The flow index is a dimensionless number that defines whether a material behaves as a Newtonian fluid $(n=1)$, i.e. its viscosity is not directly affected by the amount of shear strain. Fluids with $n<1$ are characterised as shear-thinning, whereas for dilatant or shear thickening fluids $n>1[30,54,56]$. 

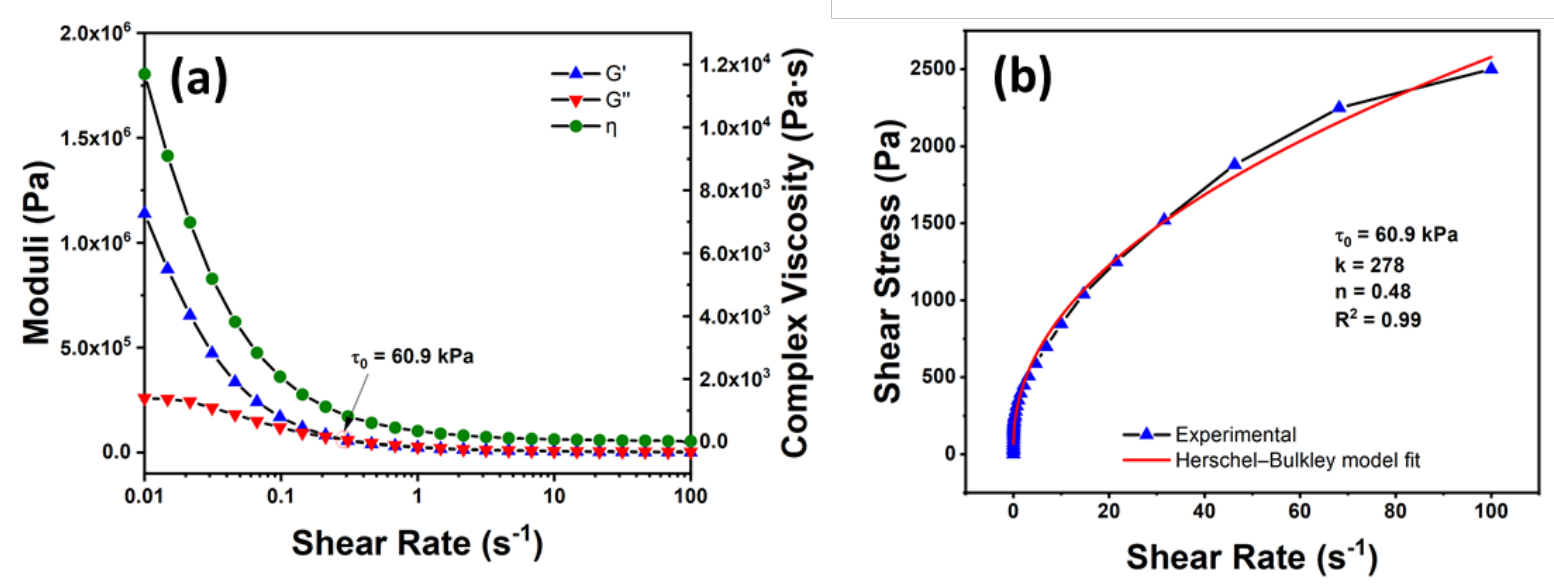

Figure 3-Rheology data of BMO ceramic pastes used for 3D printing. (a) Storage, loss modulus and complex viscosity vs. shear rate and (b) shear stress vs. shear rate.

\subsection{Phase structure}

Figure 4a-b shows the room-temperature XRD patterns for the BMO powders and sintered samples in the $640-680^{\circ} \mathrm{C}$ temperature range for dwell times of 2 and 4 hours. The diffraction peaks for the BMO powder after calcination and milling, were indexed to the monoclinic $\beta$-BMO phase (ICDD PDF 33-0209) with P2 $1 / \mathrm{m}$ space group and lattice parameters $a=11.954 \AA$, $b=10.81 \AA, c=11.89 \AA, b=$ $90^{\circ}$. No traces of secondary phase were identified, suggesting the pure synthesis of single phase $\beta$ BMO using the solid-state method. The theoretical density of the powder calculated using XRD data was $\rho=6.5 \mathrm{~g} / \mathrm{cm}^{3}$.

Between $640-660^{\circ} \mathrm{C}$, the diffraction patterns from all the 3D printed and sintered samples fired for 2 and 4 hours, are indexed to the monoclinic $\beta-B M O$ phase (ICDD PDF 33-0209). However, at $670^{\circ} \mathrm{C}$ (both 2- and 4-hours dwell time), trace amounts of the monoclinic $\mathrm{\gamma}-\mathrm{Bi}_{2} \mathrm{MoO}_{6}$ phase (ICDD PDF 330208) appear. This is evident through the diffraction peak at $2 \vartheta=28.2^{\circ}$ that corresponds to the $\{131\}$ lattice plane of the $\gamma-\mathrm{Bi}_{2} \mathrm{MoO}_{6}$ phase; the rest of the diffraction peaks are superimposed with the peaks of the $\beta$-BMO phase. This is in agreement with previous findings, that reported partial decomposition of the $\beta-\mathrm{Bi}_{2} \mathrm{Mo}_{2} \mathrm{O}_{9}$ phase to $\alpha-\mathrm{Bi}_{2} \mathrm{Mo}_{3} \mathrm{O}_{12}$ and $\psi-\mathrm{Bi}_{2} \mathrm{MoO}_{6}$ phases above $650^{\circ} \mathrm{C}[24,25]$. Finally, diffraction patterns from the $3 \mathrm{D}$ printed samples sintered at $680^{\circ} \mathrm{C}$, are indexed to $\beta-\mathrm{Bi}_{2} \mathrm{Mo}_{2} \mathrm{O}_{9}$ and $\alpha-\mathrm{Bi}_{2} \mathrm{Mo}_{3} \mathrm{O}_{12}$ (ICDD PDF 21-0103) monoclinic phases, respectively, together with the monoclinic $\gamma-\mathrm{Bi}_{2} \mathrm{MoO}_{6}$ phase (ICDD PDF 33-0208). No significant difference in phase composition are noted between the samples fired for 2 and 4 hours. However, for $680^{\circ} \mathrm{C}$ sintering temperature and 4 hours dwell time, there is a 
change in the intensity of the $\{600\}$ and $\{006\}$ reflections at $2 \vartheta=45.5^{\circ}$ and $45.7^{\circ}$, suggesting the onset of preferential grain growth.
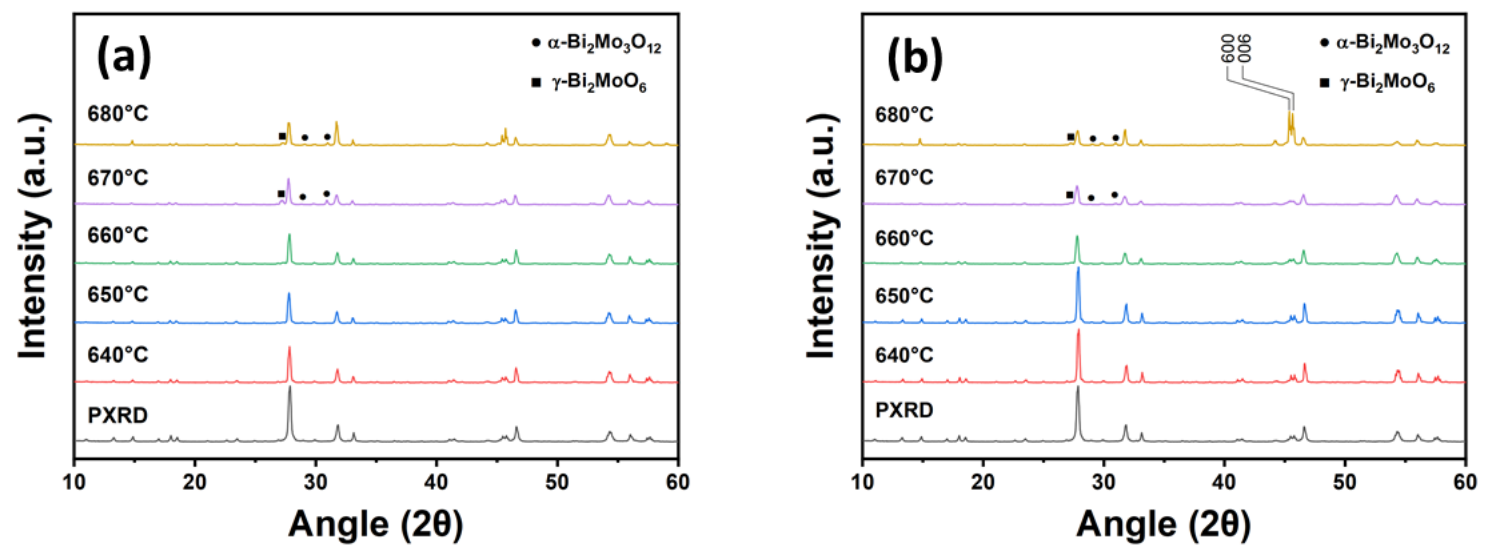

Figure 4 - XRD patterns of BMO 3D printed samples, fired at $640-680^{\circ} \mathrm{C}$ for (a) 2 hours and (b) 4 hours.

\subsection{Microstructure}

Figure 5a-t shows a range of SEM images from the surface and polished cross-sections of the 3D printed and sintered BMO specimens, fired $2-4$ hours in the temperature range $640-680^{\circ} \mathrm{C}$. Grain growth and porosity reduction are evident with increasing temperature. Porosity significantly improved at $670^{\circ} \mathrm{C} / 2$ hours, however, several pores still exist within the ceramic body (Figure $5 \mathrm{~d}, \mathrm{n}$ ). Extending the sintering period to $670^{\circ} \mathrm{C} / 4$ hours improved densification, as evidenced by a further reduction in porosity (Figure $5 \mathrm{i}, \mathrm{s}$ ). At $670^{\circ} \mathrm{C}$, several rod-like elongated grains of $\mathrm{Y}-\mathrm{Bi}_{2} \mathrm{MoO}_{6}$ are present on the surface (shown with a red arrow in Figure $\mathbf{5 d}$ ), verifying the XRD analysis discussed in Section 3.3.

For the sintering temperature of $680^{\circ} \mathrm{C}$, intergranular porosity at the surface of the samples reduces as the BMO grains enlarge (Figure 5e). However, within the cross-sections, large pores appear together with cracks, as shown in Figure 5o,t due to the formation of interspace between the grains of the $\beta$-BMO phase, as they elongate following a preferential growth regime normal to the $\{600\}$ and $\{006\}$ lattice planes, as confirmed by the XRD data in Section 3.3. 

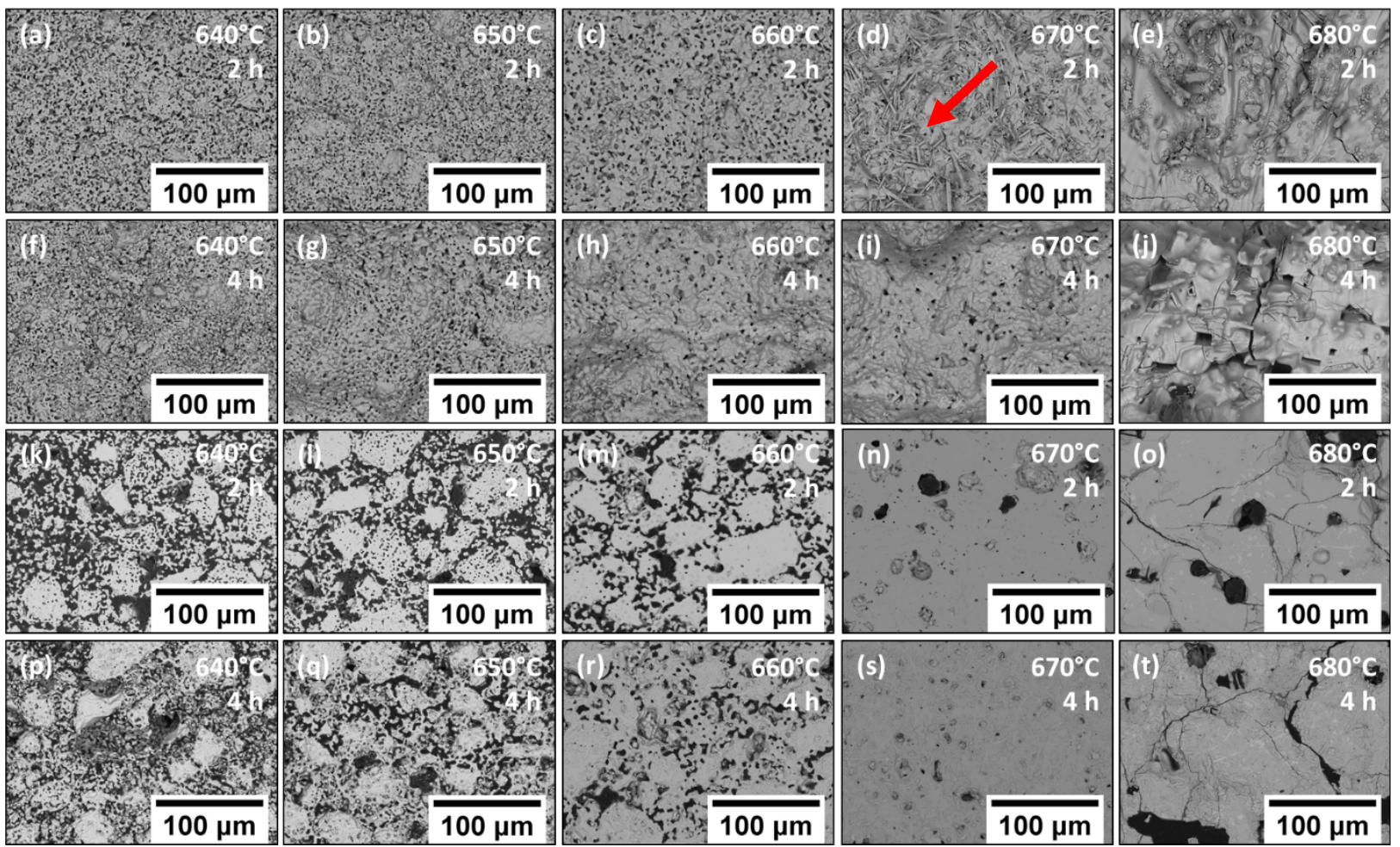

Figure 5 -SEM micrographs of the $(a-j)$ surface and $(k-t)$ polished cross-sections of the sintered $B M O$ ceramic samples, as a function of temperature and duration. The red arrow in subfigure (d) denotes the rod-like structure of $\mathrm{\gamma}-\mathrm{Bi}_{2} \mathrm{MoO}_{6}$.

\subsection{Microwave dielectric and physical properties}

Figure 6 a shows the $\varepsilon_{r}$ and $\tan \delta$ of the 3D printed samples, fired $2-4$ hours at $640-670^{\circ} \mathrm{C} . \varepsilon_{r}$ values increase as a function of sintering temperature until $670^{\circ} \mathrm{C}$ and then decrease at $680^{\circ} \mathrm{C}$. Prolonging the duration of sintering improves densification, which in turn improves $\varepsilon_{r}$. However, this effect is more noticeable in the temperature range of $640-660^{\circ} \mathrm{C}$ and is less pronounced above $670^{\circ} \mathrm{C}$. The highest value of $\varepsilon_{r}=34.23 \pm 1.19$ with $\sigma\left(\varepsilon_{r}\right)<2 \%$ is recorded for samples sintered 4 hours at $670^{\circ} \mathrm{C}$. The behaviour of $\varepsilon_{r}$ is in good agreement with the densities shown in Figure $6 \mathbf{b}$. The highest apparent density obtained in this work was $\rho=5.98 \pm 0.06 \mathrm{~g} / \mathrm{cm}^{3}$, corresponding to a relative density of $92 \%$ for the 3D printed samples processed at $670^{\circ} \mathrm{C}$. Despite $\rho_{r}$ being below $100 \%, \varepsilon_{r}$ of the 3D printed samples is very close to samples produced by pressing and sintering [24,57].

$\tan \delta$ exhibited a continuous and linear reduction with increasing temperature, as shown in Figure 6a. The lowest value of $\tan \delta(0.0006 \pm 0.00002)$ was recorded at $680^{\circ} \mathrm{C}$. The $3 \mathrm{D}$ printed $\mathrm{BMO}$ ceramics that are presented in this experimental study achieved one order of magnitude lower $\tan \delta$ compared to the materials currently used in microwave engineering and telecommunications industry $[58,59]$. 

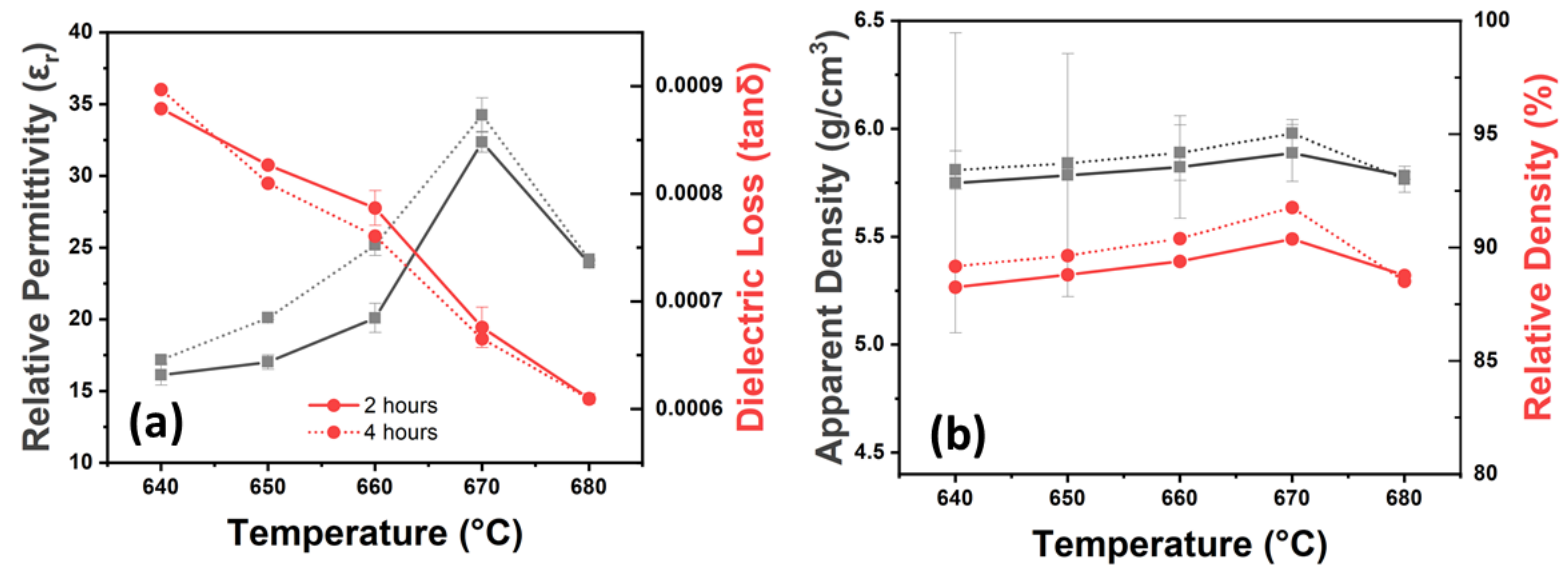

Figure 6 - The effect of sintering temperature on the microwave dielectric properties of additive manufactured BMO ceramic samples: (a) relative permittivity and dielectric loss, (b) apparent and relative density.

Figure 7 shows the behaviour of $Q \times f$ of the $3 D$ printed BMO samples fired $2-4$ hours at $640-680^{\circ} \mathrm{C}$. For the samples sintered 2 hours, $Q \times f$ increases as a function of temperature from $9865 \pm 85 \mathrm{GHz}$ at $640^{\circ} \mathrm{C}$ to $10,300 \pm 100$ at $650^{\circ} \mathrm{C}$ and remained stable until $660^{\circ} \mathrm{C}$. The recorded values in the $640-$ $660^{\circ} \mathrm{C}$ temperature range are similar to previously published data [25,57]. At $670^{\circ} \mathrm{C}, Q \times f$ reduces to $9728 \pm 112 \mathrm{GHz}$ and then increases up to $12,428 \pm 97 \mathrm{GHz}$ for samples fired at $680^{\circ} \mathrm{C}$.

This erratic change in $Q \times f$ is ascribed to the interplay between the three phases of BMO $(\alpha, \beta$ and $\gamma)$ that co-exist in samples fired at $670-680^{\circ} \mathrm{C}$, as observed in the XRD data in Section 3.3. The $Q \times f$ for BMO samples fired 4 hours, followed a similar trend over the same temperature range. The inverse effect though is observed for the samples sintered at lower temperatures $640-660^{\circ} \mathrm{C}$, possibly due to the grain size increase over prolonged sintering times that causes reduction in $Q x f[60]$.

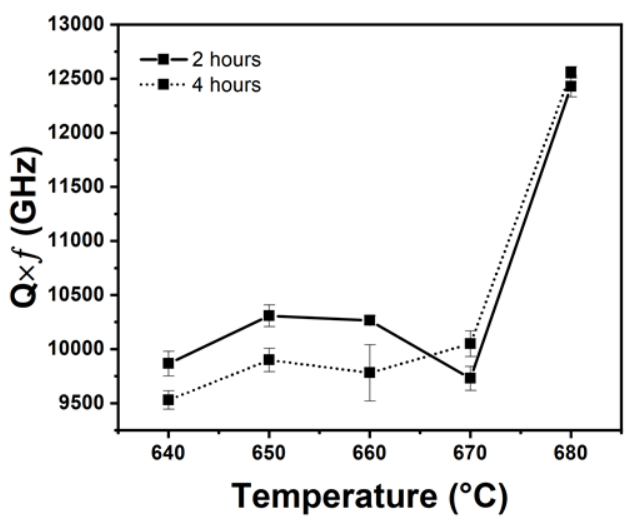

Figure 7 - The effect of sintering temperature on the microwave quality factor of $3 D$ printed $B M O$ ceramic samples 


\section{Conclusions}

Low-loss and low sintering temperature $\beta-\mathrm{Bi}_{2} \mathrm{Mo}_{2} \mathrm{O}_{9}(\mathrm{BMO})$ microwave ceramics were successfully synthesised by additive manufacturing. Material extrusion, a versatile 3D printing process, was used to produce three-dimensional test samples which were then characterised using SEM, XRD and MW property measurements. The major findings are summarised in the following bullet points:

- A combination of $0.2 \mathrm{~mm}$ layer thickness, $5 \mathrm{~mm} / \mathrm{s}$ printing speed and $0.45 \mathrm{~mm}$ hatch spacing, using a $0.5 \mathrm{~mm}$ tapered nozzle, produced stable green bodies, without macroscopic printing failures.

- Thermal debinding followed by densification at $670^{\circ} \mathrm{C}$ for 4 hours in static air, resulted in dense BMO ceramics $\left(\rho_{r}=92 \%\right)$ with good microwave dielectric properties of $\varepsilon_{r}=34.2$ and $Q \times f=$ $10,050 \mathrm{GHz}$.

- The 3D printed and fired BMO ceramics presented in this paper, demonstrated very low loss values of $\tan \delta=0.0007$, an order of magnitude lower than currently used materials in the telecommunications industry.

- Sintering at $\geq 670^{\circ} \mathrm{C}$ promoted a partial phase decomposition of $\beta-\mathrm{Bi}_{2} \mathrm{Mo}_{2} \mathrm{O}_{9}$ to $\alpha-\mathrm{Bi}_{2} \mathrm{Mo}_{3} \mathrm{O}_{12}$ and $\gamma-\mathrm{Bi}_{2} \mathrm{MoO}_{6}$, resulting in a multiphase fired sample with reduced $\varepsilon_{r}$.

- The $\beta-\mathrm{Bi}_{2} \mathrm{Mo}_{2} \mathrm{O}_{9}$ phase, exhibited a preferential grain growth when fired at $680^{\circ} \mathrm{C}$, creating interspace between the grains and resulting in an increase of porosity and cracks.

- Material extrusion 3D printing is a promising candidate for fabricating ceramic components to be used in microwave and RF applications, with high repeatability.

\section{Acknowledgements}

This work was funded by EPSRC research grant SYMETA (EP/N010493/1). The authors would like to thank the technicians of the Loughborough Materials Characterisation Centre (LMCC) for their help with the analytical equipment. 


\section{Declaration of competing interests}

The authors declare that they have no known competing financial interests or personal relationships that could have appeared to influence the work reported in this paper.

\section{CRediT}

Athanasios Goulas: Conceptualization, Methodology, Investigation, Visualization, Writing - original draft. George Chi-Tangyie: Investigation, Writing - review \& editing. Dawei Wang: Investigation, Writing - review \& editing. Shiyu Zhang: Investigation, Writing - review \& editing. Annapoorani Ketharam: Investigation, Writing - review \& editing. Bala Vaidhyanathan: Conceptualization, Supervision, Writing - review \& editing. Ian M. Reaney: Conceptualization, Supervision, Writing review \& editing. Darren A. Cadman: Conceptualization, Supervision, Writing - review \& editing. Will G. Whittow: Conceptualization, Supervision, Writing - review \& editing. John (Yiannis) C. Vardaxoglou: Conceptualization, Supervision, Writing - review \& editing. Daniel S. Engstrøm: Conceptualization, Supervision, Writing - review \& editing.

\section{Data availability}

The raw/processed data required to reproduce these findings cannot be shared at this time as the data also forms part of an ongoing study. 


\section{References}

[1] D. Zhou, L.X. Pang, D.W. Wang, C. Li, B.B. Jin, I.M. Reaney, High permittivity and low loss microwave dielectrics suitable for $5 \mathrm{G}$ resonators and low temperature co-fired ceramic architecture, J. Mater. Chem. C. 5 (2017) 10094-10098. doi:10.1039/c7tc03623j.

[2] A. Raveendran, M.T. Sebastian, S. Raman, Applications of Microwave Materials: A Review, J. Electron. Mater. 48 (2019). doi:10.1007/s11664-019-07049-1.

[3] M.T. Sebastian, R. Ubic, H. Jantunen, Low-loss dielectric ceramic materials and their properties, Int. Mater. Rev. 60 (2015) 392-412. doi:10.1179/1743280415Y.0000000007.

[4] I.M. Reaney, D. Iddles, Microwave dielectric ceramics for resonators and filters in mobile phone networks, J. Am. Ceram. Soc. 89 (2006) 2063-2072. doi:10.1111/j.1551-2916.2006.01025.X.

[5] Z. Xiong, B. Tang, F. Luo, H. Yang, X. Zhang, C. Yang, Z. Fang, S. Zhang, Characterization of structure, chemical bond and microwave dielectric properties in $\mathrm{Ca} 0.61 \mathrm{Nd} 0.26 \mathrm{TiO} 3$ ceramic substituted by chromium for titanium, J. Alloys Compd. 835 (2020) 155249. doi:10.1016/j.jallcom.2020.155249.

[6] X. Zhang, B. Tang, Z. Fang, H. Yang, Z. Xiong, L. Xue, S. Zhang, Structural evolution and microwave dielectric properties of a novel Li3Mg2-: X /3Nb1-2 x /3TixO6 system with a rock salt structure, Inorg. Chem. Front. 5 (2018) 3113-3125. doi:10.1039/c8qi00956b.

[7] Z. Xiong, B. Tang, Z. Fang, C. Yang, S. Zhang, Crystal structure, Raman spectroscopy and microwave dielectric properties of Ba3.75Nd9.5Ti18-z(Al1/2Nb1/2)zO54 ceramics, J. Alloys Compd. 723 (2017) 580-588. doi:10.1016/j.jallcom.2017.06.258.

[8] D. Wang, S. Zhang, G. Wang, Y. Vardaxoglou, W. Whittow, D. Cadman, D. Zhou, K. Song, I.M. Reaney, Cold sintered CaTiO3-K2MoO4 microwave dielectric ceramics for integrated microstrip patch antennas, Appl. Mater. Today. 18 (2020) 100519. doi:10.1016/j.apmt.2019.100519.

[9] T. Ibn-Mohammed, C.A. Randall, K.B. Mustapha, J. Guo, J. Walker, S. Berbano, S.C.L. Koh, D. Wang, D.C. Sinclair, I.M. Reaney, Decarbonising ceramic manufacturing: A techno-economic analysis of energy efficient sintering technologies in the functional materials sector, J. Eur. Ceram. Soc. 39 (2019) 5213-5235. doi:10.1016/j.jeurceramsoc.2019.08.011.

[10] D. Zhou, L.X. Pang, D.W. Wang, Z.M. Qi, I.M. Reaney, High Quality Factor, Ultralow Sintering Temperature Li6B4O9 Microwave Dielectric Ceramics with Ultralow Density for Antenna 
Substrates, ACS Sustain. Chem. Eng. $6 \quad$ (2018) 11138-11143. doi:10.1021/acssuschemeng.8b02755.

[11] D. Wang, S. Zhang, D. Zhou, K. Song, A. Feteira, J.C. Vardaxoglou, W. Whittow, D. Cadman, I.M. Reaney, Temperature Stable Cold Sintered (Bi0.95Li0.05)(V0.9Mo0.1)O4-Na2Mo2O7 Microwave Dielectric Composites, Materials (Basel). 12 (2019). doi:doi:10.3390/ma12091370.

[12] D. Zhou, J. Li, L.X. Pang, D.W. Wang, I.M. Reaney, Novel water insoluble (NaxAg2-x)MoO4 (0 $\leq$ $x \leq 2$ ) microwave dielectric ceramics with spinel structure sintered at 410 degrees, J. Mater. Chem. C. 5 (2017) 6086-6091. doi:10.1039/c7tc01718a.

[13] J. Varghese, P. Ramachandran, M. Sobocinski, T. Vahera, H. Jantunen, ULTCC Glass Composites Based on Rutile and Anatase with Cofiring at $400{ }^{\circ} \mathrm{C}$ for High Frequency Applications, ACS Sustain. Chem. Eng. 7 (2019) 4274-4283. doi:10.1021/acssuschemeng.8b06048.

[14] I.J. Induja, M.T. Sebastian, Microwave dielectric properties of SnO-SnF2-P2O5 glass and its composite with alumina for ULTCC applications, J. Am. Ceram. Soc. 100 (2017) 2632-2640. doi:10.1111/jace.14804.

[15] K. Wang, T. Yin, H. Zhou, X. Liu, J. Deng, S. Li, C. Lu, X. Chen, Bismuth borate composite microwave ceramics synthesised by different ratios of H3BO3 for ULTCC technology, J. Eur. Ceram. Soc. 40 (2020) 381-385. doi:10.1016/j.jeurceramsoc.2019.09.035.

[16] J. Guo, H. Guo, A.L. Baker, M.T. Lanagan, E.R. Kupp, G.L. Messing, C.A. Randall, Cold Sintering: A Paradigm Shift for Processing and Integration of Ceramics, Angew. Chemie - Int. Ed. 55 (2016) 11457-11461. doi:10.1002/anie.201605443.

[17] J. Guo, A.L. Baker, H. Guo, M. Lanagan, C.A. Randall, Cold sintering process: A new era for ceramic packaging and microwave device development, J. Am. Ceram. Soc. 100 (2017) 669677. doi:10.1111/jace.14603.

[18] D. Wang, J. Chen, G. Wang, Z. Lu, S. Sun, J. Li, J. Jiang, D. Zhou, K. Song, I.M. Reaney, Cold sintered LiMgPO4 based composites for low temperature co-fired ceramic (LTCC), J. Am. Ceram. Soc. (2020). doi:doi:10.1111/jace.17320.

[19] M.T. Sebastian, H. Wang, H. Jantunen, Low temperature co-fired ceramics with ultra-low sintering temperature: A review, Curr. Opin. Solid State Mater. Sci. 20 (2016) 151-170. doi:10.1016/j.cossms.2016.02.004.

[20] J. Zhou, Towards rational design of low-temperature co-fired ceramic (LTCC) materials, J. Adv. Ceram. 1 (2012) 89-99. doi:10.1007/s40145-012-0011-3. 
[21] H. Jantunen, T. Kangasvieri, J. Vähäkangas, S. Leppävuori, Design aspects of microwave components with LTCC technique, J. Eur. Ceram. Soc. 23 (2003) 2541-2548. doi:10.1016/S0955-2219(03)00155-9.

[22] H. Yu, J. Liu, W. Zhang, S. Zhang, Ultra-low sintering temperature ceramics for LTCC applications: a review, J. Mater. Sci. Mater. Electron. 26 (2015) 9414-9423. doi:10.1007/s10854-015-3282-y.

[23] M. Valant, D. Suvorov, Microstructural phenomena in low-firing ceramics, Mater. Chem. Phys. 79 (2003) 104-110. doi:10.1016/S0254-0584(02)00248-1.

[24] D. Zhou, H. Wang, X. Yao, L.-X. Pang, Microwave Dielectric Properties of Low Temperature Firing Bi 2 Mo 209 Ceramic, J. Am. Ceram. Soc. 91 (2008) 3419-3422. doi:10.1111/j.15512916.2008.02596.x.

[25] D. Zhou, H. Wang, L.X. Pang, C.A. Randall, X. Yao, Bi 20 3-MoO 3 Binary system: An alternative ultralow sintering temperature microwave dielectric, J. Am. Ceram. Soc. 92 (2009) 2242-2246. doi:10.1111/j.1551-2916.2009.03185.x.

[26] A. Goulas, R.J. Friel, Laser sintering of ceramic materials for aeronautical and astronautical applications, in: Laser Addit. Manuf. Mater. Des. Technol. Appl., 2016: pp. 373-398. doi:10.1016/B978-0-08-100433-3.00014-2.

[27] W. Nawrot, K. Malecha, Additive manufacturing revolution in ceramic microsystems, Microelectron. Int. 37 (2020) 79-85. doi:10.1108/MI-11-2019-0073.

[28] H.W. Tan, T. Tran, C.K. Chua, A review of printed passive electronic components through fully additive manufacturing methods, Virtual Phys. Prototyp. 11 (2016) 271-288. doi:10.1080/17452759.2016.1217586.

[29] A. Datar, Micro-extrusion Process Parameter Modeling, (2012).

[30] Z. Fu, M. Freihart, L. Wahl, T. Fey, P. Greil, N. Travitzky, Micro- and macroscopic design of alumina ceramics by robocasting, J. Eur. Ceram. Soc. 37 (2017) 3115-3124. doi:10.1016/j.jeurceramsoc.2017.03.052.

[31] Z. Chen, Z. Li, J. Li, C. Liu, C. Lao, Y. Fu, C. Liu, Y. Li, P. Wang, Y. He, 3D printing of ceramics: A review, J. Eur. Ceram. Soc. 39 (2019) 661-687. doi:10.1016/j.jeurceramsoc.2018.11.013.

[32] K. Rane, M. Strano, A comprehensive review of extrusion-based additive manufacturing processes for rapid production of metallic and ceramic parts, Adv. Manuf. 7 (2019) 155-173. 
doi:10.1007/s40436-019-00253-6.

[33] E.C. Hammel, O.L.R. Ighodaro, O.I. Okoli, Processing and properties of advanced porous ceramics: An application based review, Ceram. Int. 40 (2014) 15351-15370. doi:10.1016/j.ceramint.2014.06.095.

[34] D. Tang, L. Hao, Y. Li, Z. Li, S. Dadbakhsh, Dual gradient direct ink writing for formation of kaolinite ceramic functionally graded materials, J. Alloys Compd. 814 (2020) 152275. doi:10.1016/j.jallcom.2019.152275.

[35] A. Goulas, S. Zhang, J.R. Mcghee, D.A. Cadman, W.G. Whittow, J.C.V. Yiannis, D.S. Engstrøm, Fused filament fabrication of functionally graded polymer composites with variable relative permittivity for microwave devices, Mater. Des. $193 \quad$ (2020) 108871. doi:10.1016/j.matdes.2020.108871.

[36] S. Zhang, R.K. Arya, S. Pandey, Y. Vardaxoglou, W. Whittow, R. Mittra, 3D-printed planar graded index lenses, IET Microwaves, Antennas Propag. 10 (2016) 1411-1419. doi:10.1049/ietmap.2016.0013.

[37] S. Zhang, D. Cadman, W. Whittow, D. Wang, G. Chi-Tangyie, A. Ghosh, A. Ketharam, A. Goulas, I. Reaney, B. Vaidhyanathan, D. Engstrom, Jy.C. Vardaxoglou, 3D Antennas, Metamaterials, and Additive Manufacturing, in: 2019 IEEE MTT-S Int. Wirel. Symp., IEEE, Guangzhou, China, China, 2019: pp. 1-3. doi:10.1109/IEEE-IWS.2019.8803909.

[38] T.L. Chang, Z.C. Chen, Y.W. Lee, Y.H. Li, C.P. Wang, Ultrafast laser ablation of soda-lime glass for fabricating microfluidic pillar array channels, Microelectron. Eng. 158 (2016) 95-101. doi:10.1016/j.mee.2016.03.034.

[39] D. Han, H. Lee, Recent advances in multi-material additive manufacturing: methods and applications, Curr. Opin. Chem. Eng. 28 (2020) 158-166. doi:10.1016/j.coche.2020.03.004.

[40] R. Gheisari, H. Chamberlain, G. Chi-Tangyie, S. Zhang, A. Goulas, C.K. Lee, T. Whittaker, D. Wang, A. Ketharam, A. Ghosh, B. Vaidhyanathan, W. Whittow, D. Cadman, Y.C. Vardaxoglou, I.M. Reaney, D.S. Engstrøm, Multi-material additive manufacturing of low sintering temperature Bi2Mo2O9 ceramics with Ag floating electrodes by selective laser burnout, Virtual Phys. Prototyp. 15 (2020) 133-147. doi:10.1080/17452759.2019.1708026.

[41] D. Zhang, W. Jonhson, T.S. Herng, Y.Q. Ang, L. Yang, S.C. Tan, E. Peng, H. He, J. Ding, A 3Dprinting method of fabrication for metals, ceramics, and multi-materials using a universal selfcurable technique for robocasting, Mater. Horizons. 7 (2020) 1083-1090. 
doi:10.1039/c9mh01690b.

[42] A. Zocca, P. Colombo, C.M. Gomes, J. Günster, Additive Manufacturing of Ceramics: Issues, Potentialities, and Opportunities, J. Am. Ceram. Soc. 98 (2015) 1983-2001. doi:10.1111/jace.13700.

[43] J. Deckers, J. Vleugels, J. Kruth, Additive Manufacturing of Ceramics : A Review, J. Ceram. Sci. Technol. 260 (2014) 245-260. doi:10.4416/JCST2014-00032.

[44] ASTM C373-88, Standard Test Method for Water Absorption, Bulk Density, Apparent Porosity, and Apparent Specific Gravity of Fired Whiteware Products, Astm C373-88. 88 (1999) 1-2.

[45] C. Lee, J. McGhee, C. Tsipogiannis, S. Zhang, D. Cadman, A. Goulas, T. Whittaker, R. Gheisari, D. Engstrom, J. (Yiannis) Vardaxoglou, W. Whittow, Evaluation of Microwave Characterization Methods for Additively Manufactured Materials, Designs. 3 (2019). doi:10.3390/designs3040047.

[46] H. Xing, B. Zou, X. Liu, X. Wang, Q. Chen, X. Fu, Y. Li, Effect of particle size distribution on the preparation of ZTA ceramic paste applying for stereolithography 3D printing, Powder Technol. 359 (2020) 314-322. doi:10.1016/j.powtec.2019.09.066.

[47] M. Faes, H. Valkenaers, F. Vogeler, J. Vleugels, E. Ferraris, Extrusion-based 3D printing of ceramic components, Procedia CIRP. 28 (2015) 76-81. doi:10.1016/j.procir.2015.04.028.

[48] H. Sarraf, Evaluation of the Effect of Solid Loadings on Rheological Properties of Highly Concentrated Biocompatible Nanoparticle Suspensions, Nanotechnol. Nanomedicine\&Nanobiotechnology. 3 (2016) 1-7. doi:10.24966/ntmb-2044/100010.

[49] A. M'Barki, L. Bocquet, A. Stevenson, Linking Rheology and Printability for Dense and Strong Ceramics by Direct Ink Writing, Sci. Rep. 7 (2017). doi:10.1038/s41598-017-06115-0.

[50] L. Rueschhoff, W. Costakis, M. Michie, J. Youngblood, R. Trice, Additive Manufacturing of Dense Ceramic Parts via Direct Ink Writing of Aqueous Alumina Suspensions, Int. J. Appl. Ceram. Technol. 13 (2016) 821-830. doi:10.1111/ijac.12557.

[51] E. Feilden, E.G.T. Blanca, F. Giuliani, E. Saiz, L. Vandeperre, Robocasting of structural ceramic parts with hydrogel inks, J. Eur. Ceram. Soc. 36 (2016) 2525-2533. doi:10.1016/j.jeurceramsoc.2016.03.001.

[52] J.E. Smay, S.S. Nadkarni, J. Xu, Direct writing of dielectric ceramics and base metal electrodes, Int. J. Appl. Ceram. Technol. 4 (2007) 47-52. doi:10.1111/j.1744-7402.2007.02118.x. 
[53] J. Bourret, I. El Younsi, M. Bienia, A. Smith, P.M. Geffroy, J. Marie, Y. Ono, T. Chartier, V. Pateloup, Micro extrusion of innovative alumina pastes based on aqueous solvent and ecofriendly binder, J. Eur. Ceram. Soc. $38 \quad$ (2018) 2802-2807. doi:10.1016/j.jeurceramsoc.2018.02.018.

[54] M. Pospischil, K. Zengerle, J. Specht, G. Birkle, P. Koltay, R. Zengerle, A. Henning, M. Neidert, C. Mohr, F. Clement, D. Biro, Investigations of thick-film-paste rheology for dispensing applications, Energy Procedia. 8 (2011) 449-454. doi:10.1016/j.egypro.2011.06.164.

[55] S. Mueller, L. E.W., H.M. Mader, The rheology of suspentions of solid particles, Proc. R. Soc. A. (2009) 291-300. doi:10.1007/BF01432034.

[56] M.V. Ghica, M. Hîrjău, D. Lupuleasa, C.E. Dinu-Pîrvu, Flow and Thixotropic Parameters for Rheological Characterization of Hydrogels, Molecules. 21 (2016). doi:10.3390/molecules21060786.

[57] D. Wang, B. Siame, S. Zhang, G. Wang, X. Ju, J. Li, Z. Lu, Y. Vardaxoglou, W. Whittow, D. Cadman, S. Sun, D. Zhou, K. Song, I.M. Reaney, Direct Integration of Cold Sintered, Temperature-Stable Bi2Mo2O9-K2MoO4 Ceramics on Printed Circuit Boards for Satellite Navigation Antennas, J. Eur. Ceram. Soc. (2020) 0-1. doi:10.1016/j.jeurceramsoc.2020.04.025.

[58] A. Khan, R. Nema, Analysis of Five Different Dielectric Substrates on Microstrip Patch Antenna, Int. J. Comput. Appl. 55 (2012) 40-47. doi:10.5120/8826-2905.

[59] M.T. Sebastian, H. Jantunen, Low loss dielectric materials for LTCC applications: a review, Int. Mater. Rev. 53 (2008) 57-90. doi:10.1179/174328008X277524.

[60] S.J. Penn, N.M. Alford, A. Templeton, X. Wang, M. Xu, M. Reece, K. Schrapel, Effect of Porosity and Grain Size on the Microwave Dielectric Properties of Sintered Alumina, J. Am. Ceram. Soc. 80 (2005) 1885-1888. doi:10.1111/j.1151-2916.1997.tb03066.x. 